\title{
The use of Ethnography to Explore Meanings that Refuse Collectors Attach to their Work
}

\section{Abstract}

This paper details how the ethnographic approach can be usefully adopted in the context of researching dirty or undesirable work. Drawing on a study of refuse collectors, it shows how ethnography can enable a fuller social articulation of the experiences and meanings of a social group where conventional narrative disclosure and linguistic expression may be insufficient. Viewing ethnography as no one particular method, but rather a style of research that is distinguished by its objectives to understand the social meanings and activities of people in a given 'field' or setting, this paper highlights aspects of reproductive and 'dirty' work which may be hidden or difficult to reveal. Combining the methods of participant observation, photographic representation and interviews, we add to an understanding of dirty work and how it is encountered. We draw on Willis and Trondman's (2002) three distinguishing characteristics namely, recognition of theory, centrality of culture and critical focus to highlight some meanings men give to their work. By incorporating these issues of theory, culture and reflexivity throughout the research process, this paper highlights how Willis and Trondman's (2002) approach aids the ethnographic objective and is crucial to the understanding of representation and experience. As such, the value of this paper can be understood in terms of developing a further understanding of dirty work, which incorporates an ethnographic process and interpretation, to achieve 'rich data' on the dirty work experience. 


\section{Introduction}

This paper explores how ethnographic methods in the form of participant observation, interviews and photographic representation, can be usefully adopted in the context of researching dirty or undesirable work. We draw on a study that focused on the meanings that men attach to dirt and their experiences of dirty work involving the handling and disposal of waste (refuse collection) - part of a classed group that has arguably been invisible within both academic work and policy discourses. As Slutskaya et al (2012) have argued, looking at the butcher trade, challenges exist in terms of listening to and understanding the experiences of working class men. As they argue, some groups might not be used to narrative disclosure and may have a circumscribed relation to the written and spoken word - and therefore fail to satisfy their expressive needs through the linguistic forms available to them (Charlesworth, 2000). This makes reliance on linguistically based method alone unsatisfactory in terms of enabling full expression of meanings and experiences. In this paper, we accordingly show how narratives of participants can be enriched and given greater meaning through the ethnographic approach - based on active participation in daily work and photographic representation of its routines and practices in addition to more conventional conversation based interviews. Informed by Willis and Trondman's (2002) approach to ethnography, detailed below, we seek to highlight what ethnographically based participant observation, photographic representation and interviews may add to our understanding of dirty work and how it is encountered.

Refuse collection, as an occupation that is concerned with dirt's removal and the handling or manner of its return, conforms to Ashforth and Kreiner's (1999) notion of physically tainted work i.e. work that involves direct contact with physical dirt or danger. Such work is often undertaken by those at the lower end of the social hierarchy. As Douglas (1966) argues, our ideas of dirt, as impurity are an expression of symbolic systems that "offends against order" (Douglas, 1966, p. 45) so that boundaries are constructed between the orderly and the disorderly, substantiating the threat of 
contamination if these boundaries are transgressed. In this way, avoidance rules means that occupations that deal with polluting, physical dirt are routinely carried out by members of 'lower classes', separated socially from other groups (Dick, 2005; Hughes, 1958; Roberts, 2001; Skeggs, 2004). Proximity to dirt accordingly constitutes a divide between those who can withdraw from whatever bears traces of contamination and impurity and those who have little choice in the jobs they do. Further, from Hughes (1958), social status is implicated in how dirty work is managed and experienced. Thus, dirty work undertaken by those of a higher standing (e.g. bodily care performed by doctors) can be 'integrated into the whole' whereby contact with dirt can be mitigated by other, more positive and socially privileged aspects of identity. Those further down the hierarchy may have fewer status shields to manage tainted effects.

Our research sought to reinvigorate an interest in class as a category that is integral to understandings of (dis)advantage - through the diverse ways in which class "shapes and goes on shaping the individuals we are and the individuals we become" (Reay, 1998, p. 259). In this respect, less skilled men have arguably become increasingly marginalised within a labour market that gives priority to 'clean' value-adding work (Bolton \& Houlihan, 2009; Gregg \& Wadsworth, 2003). We accordingly sought to explore the meanings that working class men attach to dirty work, a neglected area of research, as a way of understanding class based disadvantage.

Our paper is organised as follows; first we discuss the ethnographic method, presenting Willis and Trondman's (2002) interpretation of the ethnographic process. Secondly we discuss the characteristics and work routines of refuse collection after which we detail how the research project was carried out. We then present three sections which are organized around each of Willis and Trondman's characteristics of ethnographic research to highlight a) how dirt is perceived, b) the 
significance of lack of recognition and a strong team based approach to work, and c) the incorporation of power relations and reflexivity in dirty work research. In our Conclusion we discuss the contribution of the paper in terms of developing understandings of dirty work, of applying Willis and Trondman's (2002) specific ethnographic process and interpretation and of operationalizing a three tiered ethnographic approach to achieve 'rich data' on the dirty work experience.

\section{Ethnographic Research}

As Tyler (2012) has pointed out, ethnographic methods can bring into focus the ways in which dirty work is enacted and experienced. The use of ethnography in social sciences more generally is both exalted and criticised for its fluid and flexible analytical approach. On the one hand it can be said that ethnography suffers from a lack of definitional clarity and that its use alters in different ways depending on the academic discipline and tradition (O'Reilly, 2005). In its simplest and most base form, ethnography is best characterised by its defining feature of participant observation applied to any small-scale research that is carried out in the field of everyday settings (Savage, 2000). However, such an operationalisation often views the ethnographic method to be synonymous with that of participant observation. As Hammersley and Atkinson (1983) detail, there is a need to distance the ethnographic method from simply that of participant observation and move closer towards a more fluid conceptualisation of ethnography. In this sense ethnography has no one particular method of data collection but rather is best viewed as a style of research that is distinguished by its objectives to understand the social meanings and activities of people in a given 'field' or setting (Brewer, 2000). From this perspective of understanding people's actions and experiences of the world, ethnography is best characterised as a 'family of methods' which involves direct and sustained social contact with agents in the field to understand the representations of experience (O'Reilly, 2005; Willis \& Trondman, 2002). Each method seeks to further articulate the presentation and explanation of a culture in which experience is located. Further, experience itself also needs to be entrenched in the 
flow of history (Brewer, 2000; Willis \& Trondman, 2002). Under these terms, the ethnographic process is not the application of a single research method, but rather an understanding of representation and experience through both empirical and theoretical application.

Central to the ethnographic tradition is the study of culture and external influence on individual action as an empirical focus on society itself. As argued by O'Reilly (2005), in order to study culture and experience, one must simultaneously represent society as the perpetual process of social integration and harmonious interaction. In order to anchor this theoretical interpretation of ethnography, Willis and Trondman (2002) present two important methodological contexts to ethnographic inquiry. First, through the study of symbolic forms, patterns, discourses and practices experience can be located within a presentation of culture and given more solid form and shape. Second, experience needs to be based in the wider context of history in order to contextualise and maintain experience within the form of external structures. Alongside this, it is possible to add to a third stipulation: analytical reflexivity is required from the researcher to remain 'self-conscious' of his/her own active input and method selection (Atkinson, et al., 2001; Brewer, 2000). Taken together, ethnography represents the study of experience as seen through the (re)production of actions and symbols of communication in the cultural 'field' that are contextualised by external discourses of power and restriction. However, like all forms of observation, the presence of the researcher - along with their own subjective interpretations - will have a critical impact on the social outcomes being studied. In this manner, the individuals who form the focus of the study should be viewed as "part subject" and "part object" (Thompson, 1978) to fully articulate the individual as a voluntary agent defining the role of experience as well as being involuntarily defined by opposing structures of culture. 
Pooling together the vagaries of the ethnographic approach, this paper follows Willis and Trondman's (2002, pp. 396-398) distinguishing characteristics as the basis of a definitional operationalisation of the ethnographic approach. First is the recognition of the role of theory throughout the ethnographic process (in study and writing). In particular this is achieved through the use of theoretically informed ethnographic writing which distinguishes itself from the 'thick description' of journalism by relying on an ability to 'visualise' and 'understand' culture through sonic, visual and tactile methods of research (Brewer, 2000; Fabian, 1983). Second, is the centrality of culture, that is the imperative for all social groups to find and make their 'lived' meanings in the context a temporally and spatially positioned society. Third, is a critical focus in research and writing which makes explicit the lived in 'conditions of being' that are informed by the lived social relations which embody, mediate and enact constructions of power. As such ethnography is an iterativeinductive process (O'Reilly, 2005) which retains an open and flexible design, led by the outcomes of reflexive research in the field.

The ethnographic tradition has historically been strongly connected to the understanding of experience for foreign (i.e. colonial) or marginalised Others (see Brewer, 2000; O’Reilly, 2005). In both cases the utility of ethnography represents an ability to better understand a way of life alien to the researcher and the mainstream collective imagination. More recently this methodological approach has been applied by Neyland (2008), Ybema et al (2009) and Tyler (2012) in the context of everyday experiences of organisational life. While ethnography remains an underused tool within the field of organisational studies, such studies have put the ethnographic process 'on the radar' of empirical work being conducted in the area. From this it is possible to glean how ethnography can be used to better enable our understanding of the day-to-day reproduction of labour, experience and meaning in the work environment. In the context of men in 'traditional' working-class jobs, ethnography represents not just a methodological and procedural approach towards experience, but 
a closer, symbolic imagining of experience, constrained by structures of culture and power. By watching, listening, asking questions and sharing experiences in the field, the ethnographic process allows the researcher to acquire a close sense of the social structures and embedded cultures from the perspective of those who live it (Hammersley \& Atkinson, 1983). In this context, conclusions are drawn from the everyday routines, practices and experiences that constitute social action within the institution of the workplace. As such, the ethnographic approach aims to achieve a deeper level of interaction through a 'reflexive engagement' that lends the participants a voice through the development of a reciprocal research encounter (Karnielie-Miller, et al., 2009). Furthermore, the use of ethnography in this context sheds light on the normative assumptions, embedded cultures and hidden exchanges of workers through the perspective of everyday organisational life (Ybema, et al., 2009). Much as the early ethnography of the Chicago School sought to fill in the gaps of the hidden lives of a marginalised workforce in an industrialising urban environment, this paper highlights the utility of this tradition in the contemporary context in exploring the meanings attached to dirt and the experiences of men undertaking dirty work. While not offering a step-by-step account of how to 'do' ethnography, this paper includes a presentation of how the three methods, when ethnographically informed, can combine to enhance our understanding of lived in experience from the perspective of those who live it - especially where traditional linguistic forms of interaction are either unavailable or insufficient.

\section{Dirty Work and Refuse Collection}

In a context of a possible erosion of working class 'reference points' such as trade unions, affordable public housing and a labour party committed to the welfare of this group (Charlesworth, 2000; McDowell, 2003; Sennett \& Cobb, 1972), working class jobs, particularly those deemed appropriate for men, routinely involve a relatively dangerous or dirty environment, boring or mundane tasks, close supervision and limited opportunities for upward mobility (McDowell, 2003; Bolton \& 
Houlihan, 2009). As Skeggs $(1997 ; 2004)$ has argued, this has exposed the working class to detrimental moral evaluations as referred to above. Here, as authors have claimed in the context of working class men (e.g. Willis, 1977; Connell, 2000; 2005), recognition and respect are often sought through muscularity and strength where value is attached to the development and practice of physical capital and skill. In other words, as Sennett and Cobb (1972) have argued, working class men may resist such devaluation through the elevation of their physical abilities and capacities for endurance - with implications for how dirty, physical work may be perceived and experienced.

An overwhelmingly masculine occupation, refuse collection involves the handling and disposal of dirt and waste discarded by households and individuals. This representation of refuse collection conforms to the ONS (2010) classification of an 'elementary' cleaning occupation which requires little or no formal or on the job training. The lived experiences of those carrying out the work are not only considered invisible in the sense of receiving little or no outside recognition but have the potential, as Ashforth and Kreiner (1999) argue, to impinge on individual feelings of self-worth. Refuse collection therefore was seen to represent a reproductive task closely linked to products of dirt and waste which is negatively positioned in the minds of the public. Moreover, refuse collection holds the potential to highlight how dirt may be encountered on a daily basis and how, through the meanings attached to the work, status and self-respect may be protected and enhanced by the everyday actions of the individuals involved.

\section{The Research Project}

The project was conducted in the summer of 2011 by a team of four researchers ( 2 women and 2 men). One man (who, as a skilled photographer, also took photographs of daily routines) and one 
woman collected data through participant observation and by conducting interviews. All four researchers were involved in data analysis detailed below.

The work of refuse collection, like many other work environments, can be a source of pain, drudgery and boredom as well as a source of joy, energy and fulfilment of work based tasks (Wrzesniewski, 2003). Nonetheless, the day-to-day nature of the work is generally repetitive and routine, following the same weekly route with little to no variation. This weekly cycle is repeated throughout the year, regardless of weather conditions or the varying amounts of rubbish disposal (i.e. increased loads during the summer or after public holidays). Our experiences in the field identified three key elements of the job : firstly the 'pullers' must go into front gardens and down alleys to pull out all of the black refuse sacks (or recycling bins) and place them in piles by the side of the road for pickup. This group starts earliest but will also finish before the other two groups. The 'loaders' then work alongside the truck, throwing the bags into the back of the vehicle. Twice daily (usually around 9.30am and then $1 \mathrm{pm}$ ) this routine is interrupted by a visit to the dump to empty the rubbish containers at the back. Finally, the trucks are driven by 'bankers' - skilled drivers who normally head the team and who must be able to reverse round tight corners and manoeuvre in narrow suburban streets. This job is seen to be the most desirable of the three since the driver gets to stay inside the cab throughout the day. Together, these team based work practices engender a strong occupational culture based on camaraderie and a valued and pleasurable humour ("having a crack") - providing defence against assaults on identity (from the public and from the grim nature of the work). The day starts early. Workers would normally be required to be at the depot by $6.00 \mathrm{am}$ from where they head out in their various teams. While this experience would be limited to the specific London Boroughs that formed that basis of our sample, what is expected to be more generalizable is the manner in which the teams are usually held together to provide a sense of continuity and unity. 
However, the increased reliance on temporary 'agency' workers more recently means that this is not always the case as teams have to work with higher turnover of staff.

A process of direct sampling was adopted through telephone and email contact with councils and with contractors in and around London. While direct sampling would not traditionally be countenanced as a method, issues around access meant that the project was reliant on the cooperation and agreement of managers and supervisors. One council in Greater London and two contractors agreed to take part in the study, granting permission for two days in which we, the research team, could come on-site and work alongside the participants as well as conduct interviews 'on the job'. Negotiation had to be made as to what sort of access we would be granted, with participant observation key. Each morning, when we arrived, we found ourselves standing in the 'yard' waiting alongside all the other workers, waiting to discover which driver they would be working alongside that day. The first day we were placed with a 'black bags' refuse team and on the second day we requested to work with the recycling team. Given the level of competition between the two groups (with recycling not seen by the 'black bags' as 'proper' work given that they were dealing with lighter and cleaner material) it seemed to be a fruitful opportunity to understand the existing nuances that operate within each job. While there was a concern that this 'top-down' process of access might lead to a lack of disclosure on the part of participants, with our presence being viewed as part of some management objective, this concern dissipated once the process of data collection got underway. The presence of the two members of the research team, who engaged fully in all disposal activities of the day, generated considerable interest and amusement. This was particularly the case with the one woman researcher who, while also taking part in activities of rubbish disposal, was carefully overseen in a paternalistic manner by the all-male crew. Further, the break for the interviews was welcomed as a 'rest' from the routines of the day. In this respect, 
working alongside the men presented a chance for a more informal 'conversational' dialogue to develop with its own themes and discourses emerging.

As discussed earlier, the research drew on a three-tiered ethnographic approach of participant and non-participant observation, semi-structured interviews and photographic representation. This triangulation allowed the events of ethnographic observation to be corroborated and developed through the systematic collection of work-histories and photographic capture. In total, the two researchers collected fourteen interviews and over fifty photographs. Rather than facilitating the production of data, as in photo-elicitation (Harper, 2002), photographs gave visual image over and above textual accounts of some of the work practices that are embedded within the routines of the day. The breadth of research methods utilised aimed to, as Tyler (2012) argues, establish an ethnographic lens which can help bring into focus the ways in which dirty work may be enacted and experienced. On each of the days the research team accompanied the workers on their rounds, one member focused on conducting the interviews while the other made up of the 'lost body' by filling in for them on the street - thereby directly engaging in the daily experiences of the job. In this manner, ethnographic participation opened up the potential for a fuller articulation of habitual and mundane experiences of the job that might have otherwise gone unexplored. At the end of each working day field notes were written up to detail the events, interactions and conversations of the day.

Interviews took the form of 'conversations with a purpose' (Kvale \& Brinkmann, 2009) and included key themes such as men's occupational journeys; job opportunities presented and choices made; the daily routines of the job; the skills drawn on and developed; aspects of the work they found most challenging and those they enjoyed. Interviews were recorded and transcribed in full. Careful reading of transcripts and the field notes was undertaken by the four researchers so that 
familiarisation could take place. Upon familiarisation, the research team were able to discuss their own interpretations of the data leading to the broad themes of inquiry as identified above. After this a more detailed thematic analysis took place, using qualitative analysis software. This was undertaken by each researcher separately in the first instance with later corroboration given to emerging themes by comparing and discussing, in a reflexive fashion, individual insights and interpretations. This analytical process facilitated the identification of 'patterns of experiences' based, from Taylor and Bogdan, on 'conversation topics, vocabulary, recurring activities, meanings, feelings' (Taylor \& Bodgan, 1984, p. 131). Accordingly, 'disorderly' behaviour from the public (e.g. in terms of leaving out 'unacceptable' waste) and lack of recognition of the service provided emerged from discussions of the less pleasurable aspects of the job while humour and a strong sense of camaraderie was a source of satisfaction and enjoyment. Finally, comparisons were made across the slices of data via axial coding 'a set of procedures whereby data are put back together in new ways' (Strauss \& Corbin, 1990, p. 61) in order to elucidate the inter-relationship between themes, identify core and recurring themes, and then to explore the extent to which such themes might be indicative of more generalized phenomena. For example, from this stage, attitudes relating to the inevitability and desirability of work (in contrast to the less favourable alternative of unemployment) were found to pervade accounts of job choice, aspirations, day-to-day routines as well as its physicality and 'dirtiness'.

In cases such as this, where the research objective is to explore experiences around dealing with dirt and cultural taint which may be considered sensitive, care needs to be taken to prevent the contamination of the findings (Lee, 1993). The pre-perceived stigma attached to dirty work and the moralising of outside discourses may increase non-participation and evasive responses due to individuals expecting negative consequences, a problem which can reduce the interpretative power of the data collected (Saunders \& Thornhill, 2011). Even when confidentiality is assured, questions 
around topics perceived as sensitive are likely to result in responses that will protect the participant themselves from embarrassment and to present themselves in such a light that is positively reinforced by the researcher (Saunders \& Thornhill, 2011; Dalton, et al., 1997; Lee, 1993). As Saunders and Thornhill (2011) detail, the use of triangulation, or mixed methods, in the data collection process can increase interpretative power - providing a more complete account of experience than would otherwise have been possible. In this case, the interview process was able to explore in greater depth some of the findings which emerged from the participant observation process, while photographs presented a visual snapshot of the texture and feel of the work to add to the general 'feel' of experience.

In a less defined research situation, such as ethnographic observation, ethics become particularly relevant and were of paramount importance throughout the research process. Acknowledging that ethnography is a more extensive and invasive process, the research team sought to follow Flick's (2007, p. 96) four principles of ethically sound research. Firstly, informed consent was maintained throughout, which meant that strenuous efforts were made to ensure that no one involved in the project as a participant was left unclear about our research objectives and were given the option of refusing to take part. Before we started each day the research team was clear about what our aims and objectives were as well as what would be required of the participants. Only when we were satisfied that each member of the crew was happy with our presence did we start the data collection process. Secondly, at no point in the research process did we engage in covert observation, nor did we supply false information. The main suspicion from the participants was that we were part of a management objective; therefore it worked in our interest to dispel this preconception by disclosing our academic motivations. Thirdly, the sustained and (possibly) invasive nature of ethnographic research meant that throughout the research process participants' privacy has been ensured. No names of companies or councils who granted us access have been named since it is the ethnographic 
data that we are interested in, not information on specific company practices. The same is true for individual participants, for whom pseudonyms have been used and, where necessary, faces have been pixelated to maintain anonymity. Finally, and importantly, the accuracy of the data and its interpretation has been a leading principle.

\section{Recognition of the Role of Theory: Perceptions of dirt}

In this section we show how the combination of interviews, photographic representation and participant observation can, through visual, tactile as well as sonic methods of research, give a rich understanding of how dirt is perceived. We draw on Willis and Trondman's (2002) imperative to recognise the role of theory and to have theoretically informed ethnographic method as a guiding and fundamental principle in a research study (Brewer, 2000; Fabian, 1983). In so doing, based on the theoretical work of Douglas (1966) who conceptualised dirt as socially constructed, given meaning in context, we highlight the contingent nature of dirt and of its relational positioning. Douglas's orientation is concerned with the contingent, symbolic categorisation of dirt - founded on perceptions of dirt and pollution as matter out of place, that is the violation or corruption of cultural norms. Douglas argues that our ideas of dirt as impurity are an expression of symbolic systems in which dirt, by definition, 'offends against order' (Douglas, 1966, p. 45). Cleanliness and dirt are therefore not simply material matters but are imbued with a social and moral significance. We were accordingly alerted to the ways in which dirt may be perceived and how it may be encountered and experienced - as well as to our own feelings and sensations as we engaged, personally, with its disposal.

Informed by our theoretical lens, we were sensitive to how boundaries between the 'orderly' and the 'disorderly' may be constructed and maintained. In this respect, field notes from the first day's 
work with the crew reveal an aversion, on the part of one of the participating researchers, to proximity to and possible touching of the waste that was being disposed (while not in the notes, there was a strong smell from the bags on what was a hot working day). Here, it was anticipated that the wearing of heavy duty, rubber gloves would provide an effective barrier against the viscerality of the material being handled:

"Putting on the heavy duty red rubber gloves made me feel ready for the huge job ahead, around 1600 houses in one day, but as soon as I picked up my first bag it was clear that the gloves were not a help but a hindrance as the slick plastic of the bags slid off the rubber. Few of the others wore them - although, aware of what I might be handling, I was very reluctant to take them off."

The expressed reluctance to 'handle' dirt i.e. to avoid its contact with the skin suggests potential for feelings relating to disgust to create a distance from dirt and a desire for a barrier between dirt and the person - highlighted by Douglas as a mechanism for avoiding the threat of contamination. Further, the field notes are indicative of how dirt may be differentially perceived (given that the crew often handled the bags and their contents without the protection of gloves) so that it was not universally seen as a source of aversion or as inherently polluting.

In this respect, while generally seen as 'matter out of place' (Douglas, 1966), refuse was not necessarily perceived by the men as dirty. Rather, it became 'normalised matter' - the dispersal of which was accepted as part of daily work routines, integrated into notions of an essential service. As one refuse collector commented: "They (the public) think it's dirty but it's a job you know. Somebody's got to do it". Dirtiness was instead identified on the basis of 'out of place' matter within this 'normalised' domain. Thus, refuse collectors expressed disgust over material left for collection which transgressed boundaries of acceptable waste - such as sharp objects, cat litter or excrement. Cheap bags that split and spilled their contents were equally reviled and the need to handle the results was a source of distaste. From the interview transcripts, one collector commented: 
“People are cheapskates, they've got to pay 49p for rubber bags which do not do the job and instead of double bagging them... they overfill it with the junk, the rubbish goes everywhere [and] we get the blame."

Refuse that was inappropriately bagged was accordingly seen as 'dirty' - transgressing the boundaries of normalised waste. The photograph below provides illustration of this phenomenon and how rubbish is often deposited in small, plastic carrier bags.

Figure 1

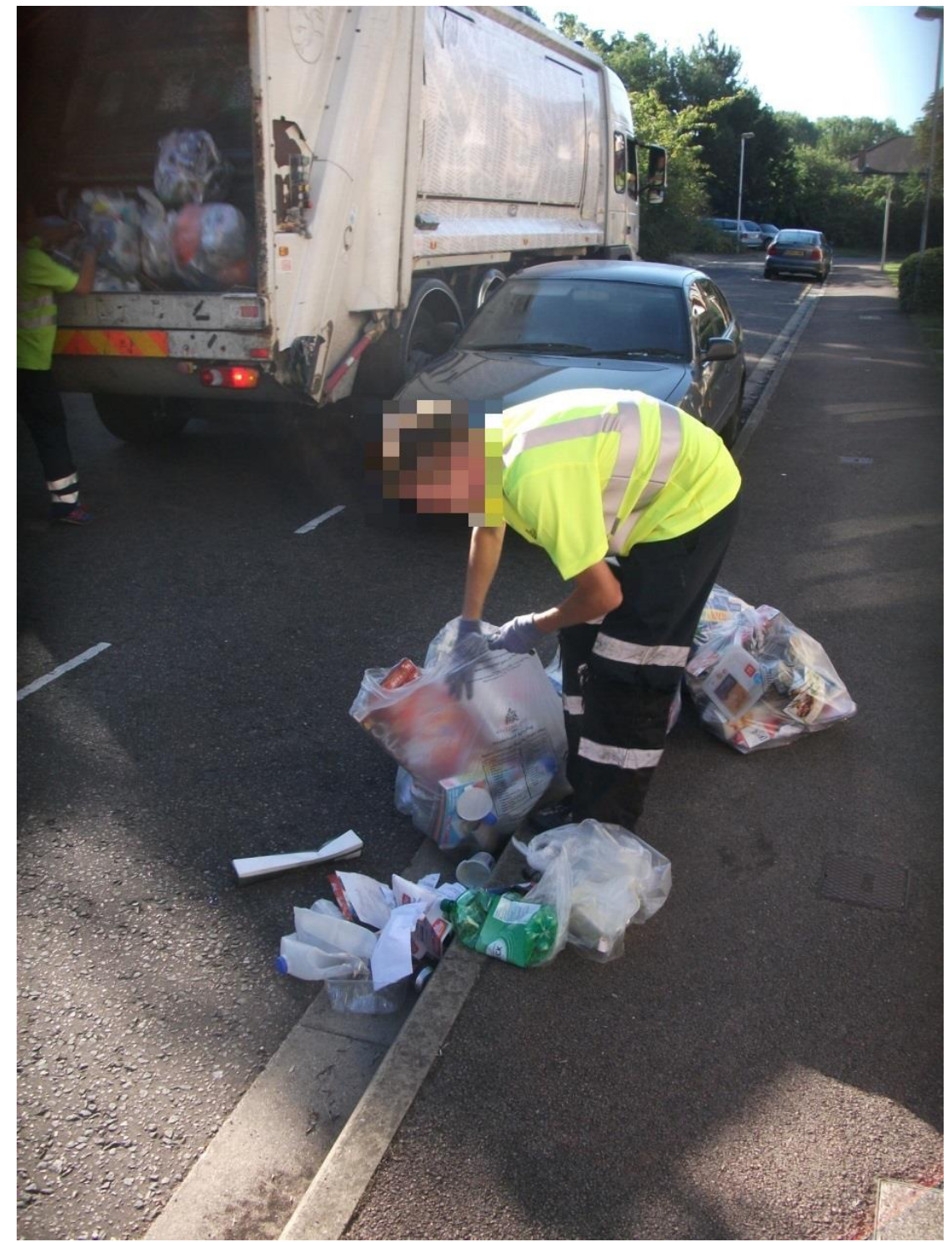

One refuse worker struggling with the overspill of rubbish. 
Contents from split and overfilled bags have scattered across the road and pavement while the collection truck waits in the middle of the street. Items are picked up by hand and re-sealed, slowing down the progress of the crew and potentially extending the working day (all rubbish has to be cleared). In Douglas's terms, dirt was thus identified by the crew as 'out of place' matter i.e. as outside the boundaries of acceptable waste and/or as 'disorder' through interference caused to the routines and speed of its removal.

In accordance with Willis and Trondman's (2002), and by drawing on Douglas's (1966) theoretically informed conceptualisation of dirt, our theoretical lens formed the basis for an understanding of how boundaries between the 'dirty' and the 'clean'; the 'orderly' and the 'disorderly' may be constructed and maintained. We were able to highlight, as illustrated in the brief example above, how the constitution of dirt can be reconfigured against a contingent axis of the clean/dirty divide. Thus, dirtiness was shown to lie outside commonly constructed boundaries and to relate to notions of (un)acceptable waste as well as to the bringing of disorder to the 'order' of dirt through disruptions in the rhythm of dirt's disposal. Participant observation allowed direct experience of the physicality of dirt (e.g. the sensations of smell and touch; the feelings of aversion) and observation of the work's routines. Photographic representation afforded visual depiction of ways in which boundaries of dirt may be encountered and transgressed. Finally, interview data gave voice to an under-researched group - allowing men opportunity to express attitudes towards and experiences of the handling and removal of waste. In so doing we arguably gained a deeper understanding of how dirt is encountered and perceived by those who must routinely deal with its removal. 


\section{The Centrality of Culture: Lack of recognition and the role of camaraderie}

Just as Wacquant argues that "one cannot understand what an instituted religion such as Catholicism is without studying in detail the structure and functioning of the organisation that supports it" (Wacquant, 2004, p. 13), the centrality of culture highlights the need to understand social experience in the context of socioeconomic constraints in which it is embedded. As Willis and Trondman (2002) highlight, there is an increased imperative for the lived meanings of social groups to be located within a temporally and spatially positioned society. That is to say, by embedding social experience in a cultural framework it is possible to understand how the beliefs, ideologies, normative assumptions and formal rule systems not only provides the scripts for bodily action, but will also positively or negatively affect meanings attached to our daily routines, cultural tastes and work experiences (Bourdieu, 1984; McDowell, 1997; Zukin \& DiMaggio, 1990). While the body remains the primary site of social experience in the ethnographic imagination, its 'lived meaning' both shapes and is shaped by surrounding cultural dispositions - something which has a direct impact on workplace behaviour (McDowell, 1997).

As is detailed in the previous section, the theoretical framework of Douglas (1966) positioned dirt as socially constructed and given meaning in context. Refuse was not necessarily perceived by the workers as dirty but as 'normalised matter' i.e. it was accepted as integral to daily work routines. However, this is set against the broader sense of disgust on the behalf of the public which influences the meanings men attach to the work and its routine. By observing the relationship between the refuse collectors and the public, we were exposed to twin sets of experience which define their day. On the one hand, the work is often seen (by outsiders and the residents whom they serve) to be lacking in value, encapsulated through experiences of non-recognition. On the other hand, there remains a strong sense of camaraderie within the teams, adding value and meaning to the experience of their work. 
Informed by Skeggs' $(1997 ; 2004)$ conceptualisation of class as a social and cultural space of relations, positions, dispositions and meanings, respectability embodies a moral authority that classifies those 'without' as dangerous, polluting, threatening and without respect. Despite the public service provided through the work, lack of recognition (of the work; of the worker) characterised the working day. It was rare for passers-by to give any form of acknowledgement (e.g. through eye contact or a greeting) and drivers were especially impatient. The way in which the workers were routinely ignored by the local residents highlighted the invisibility of the experience attached to the work. These sentiments are partially captured by the field notes recording a conversation with one of the refuse collectors:

"On the weekly rolling route, every bag that has been put out whether it is two or twenty per house must be cleared. However the men do this without any form of recognition from the public. Most of the time passers-by fail to acknowledge their presence and in the car it is even worse. "One time this driver edged closer and closer until he nudged my leg, I'm not supposed to but that time I went ballistic! All they have to do is leave five minutes early on the day we collect their rubbish, it can't be a surprise we're there after all they put the bags out!" The anger directed at drivers is obvious and understandable as the cars that did pass could not be described as being patient."

The low value placed on the work is manifest in day to day encounters that position men in detrimental terms. As the above passage highlights, for passers-by the workers are rendered largely invisible - their proximity to dirt leading arguably to low moral evaluations. This invisibility lies in contrast to the dominant, physical presence of the daily operation of rubbish removal: the large rubbish truck and the team of workers moving along often narrow residential streets where this presence is seen by drivers as a physical obstruction. 
The proximity to dirt and the low value consequently afforded to the work removes much of the good-will often attached to the performing of a public service. This negative cultural disposition not only affects the work experience but also the meaning men attach to the job. As one refuse collector commented of members of the public: "They'll say, 'Oh low life', you know, try to degrade you". Another referred in the course of an interview to the routine disparagement from peers:

"Yeah, yeah, oh they say it, they talk about dustmen in the pub, you know because obviously when I'm not at work I don't wear the uniform and I'm sitting there and you know, "oh those stupid dustmen and this, they're all as thick as dog's do and all that", you know, "well fair enough mate, keep going, you know, I'm smarter than you are, you know"'”.

As this passage highlights, the cultural taint of dirt is a position that can follow men beyond the hours of work. Another employee commented on his friend's reactions when he started the job, "they used to ask me how do I live with the smell when I get home and that? I would tell them that I get in this thing called a shower. When I get out the smell is gone". These experiences reflect a cultural disgust associated with dirt and how it is seen to adhere to the person - despite the obvious availability of washing facilities that can remove its traces. Dirt can therefore affect the lived meanings of daily practices both at work and beyond.

Despite the negative disposition which defined much of the work experience, the team based relationship and sense of camaraderie were a source of enjoyment throughout the day. As Ashforth and Kreiner (1999) argue, perceptions of a common threat (e.g. disparagement from 'outsiders') can strengthen occupational and workgroup culture leading to an articulation of occupational identity based on 'us' and 'them'. This may find particular purchase in the context of doing an essential public service and in the physical demands of the job as well as unsocial hours that limits contact with outsiders. This is partly captured in Figure 2 which, against the backdrop of the collection truck, depicts a physical togetherness and comfortable familiarity as two collectors jostle and clasp each 
other in what appears to be a humorous embrace - made clumsy by the large gloves worn by both men. Pleasure is evident in this fleeting intimacy.

Figure 2

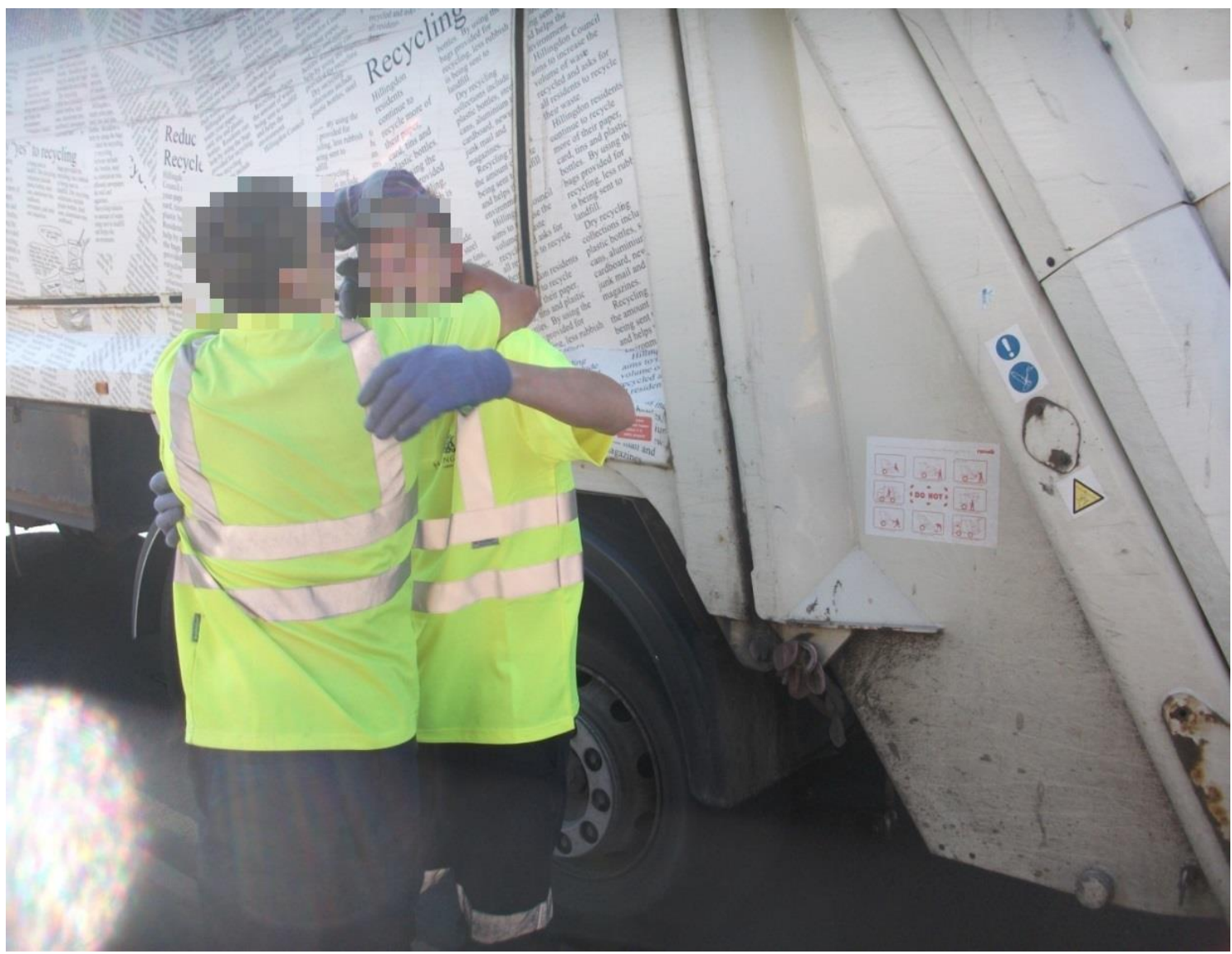

Two refuse workers engaging in a playful embrace.

Indeed, it was this sense of 'in it together' and camaraderie that was the first defining impression for the research team. The enjoyment and collective 'buzz' is evident from the field notes below, detailing the first impressions of waiting at the 'yard' at 6am on a summers morning awaiting the start of the working day:

"By 6am when we arrived there were already thirty to forty people in the yard with a constant trickle of new arrivals. First everyone had to report their presence to the coordinating officer before getting stuck in with their mates and enjoying the buzz before the work starts. The yard was full of the banter coming from an array of London accents and a crisp August morning helped keeping spirits 
high with a lot of joking and jostling between the workers. One wonders what the atmosphere is like on a dark, wet November morning, but for now everyone seemed to be enjoying the early summer's light before work."

Working and interacting alongside the participants within their familiar context enabled researchers to experience otherwise inaccessible sensory impressions, capturing the 'feel' of the work through the embodied experiences. A strong part of this was the unity and banter that formed the basis of team work. Conversations were on-going, centring predominantly on football, women, the previous day's London riots, as well as the physical demands of the job. Through the collective sense of camaraderie, physical strength and speed (the quicker the job was done the sooner they could go home), the refuse collectors were able to draw on positive aspects of working class masculinity such as hard work and physical effort (Charlesworth, 2000; Connell, 2000) and produce an experience that could counter the negative perception of the work.

Taken together, we can see how through participant observation, photographic representation and interviews, insight can be gained into the 'feel' of the work. This manifests not just in the physical effort involved and the tiredness that becomes increasingly evident through the course of the day but in the experiences of devaluation and non-recognition in the daily encounters with members of the public as well as in the more pleasurable experiences - evoked in visual form through photographic representation of humour and intimacy. More fundamentally, it is possible to place the role of culture (in the meanings attached to dirty work; in strong occupational ideologies that support work based community) in shaping both the negative and positive experiences of the job experiences that may otherwise be inaccessible and difficult to fully comprehend. 


\section{A critical focus in research and writing: power and reflexivity}

With a critical focus in research and writing, there is a need to view the subject of enquiry as a 'conditioned being'; that is to say, an active agent who embodies, mediates and enacts the structural operations of power and control (Willis \& Trondman, 2002). By situating the discourses of dirt and reproductive labour in a wider social context, the explicit lived in 'conditions of being' are seen to be informed by unequal social relations that, in Skegg's (1997) terms, position certain groups as undeserving. While the workers themselves reposition the meaning of dirt (as unacceptable waste; as disruptions to rhythms of the working day), society as a whole continue to view the work of refuse collection through the lens of stigma leading to an articulation of identity through experience and socially constructed meaning. As Ashforth and Kreiner (1999) suggest, this is based on an 'us' and 'them' dichotomy of power and influence. For the workers, despite performing an essential public service, the hours of the job limit the level of contact with outsiders and, more importantly, the true condition of their experience is shaped by negatively imposed constructions of class and dirt which comes to define their labour.

These negative evaluations have potential to also define the research encounter - raising more generalised issues about the socially contingent character of knowledge and the representation of data (Cunliffe, 2003). This is particularly pertinent in the context of researching dirty work where intrinsic power dynamics of the research are a central consideration and where differences in social position need to be scrutinized and brought into view. Following, Karnieli-Miller et al (2009), we sought 'reflexive engagement' that allows participants 'voice' and 'dignity' through the development of a reciprocal and non-hierarchical research encounter. Here, participant observation was key to creating a 'democratised' research setting. 
In this respect, as discussed earlier, while we were initially concerned that management's involvement in setting up the project would create a barrier between ourselves and the men we sought to engage, the novelty of our presence and the break afforded in the working days were often welcome. More importantly, participant observation helped to break down barriers given that, from our field notes, "we were (seen to be) willing to roll up our sleeves and give the job a go". Participant observation also gave opportunity to men to demonstrate their knowledge and skill as we often struggled to undertake the work. Field notes captured this element:

"Darrell took delight in my difficulty in swinging almost every bag into the truck, "the difference between you and me" he asserted "is that you make this job look difficult" and he was right, I am sure I did. "This job ain't difficult but it is tough for the likes of you. You need to think of it like chess... always think of the next move ahead, where are the bags? Where do I need to go?" Darrell placed a lot of pride in his ability to lift up three or even four bags in one hand, relating to his experiences as a power-lifter in the past... Aside from the weights he was able to lift pride was also placed in this ability to throw 'the right bag' from fifteen or twenty meters away. When I asked him to show me he did not back away from this claim but rose to the challenge".

Our lack of skill was the subject of good humoured banter and, as the above field notes attest, enabled men to demonstrate superior skill and strength - helping to overturn perceptions of hierarchical difference. Participant observation therefore helped to break down barriers (e.g. caused by differences in occupational positioning) and to challenge perceptions of hierarchy that may also have been instilled by the role of management in setting up the study.

Further, in recognition of the influence of relative social positioning (e.g. between participant and researcher) on modes of understanding we sought to develop a 'deep attentiveness' (Charlesworth, 2000) based on an engaged and committed interaction in which one 'helps the other to articulate the pieces that have contributed to the totality of their experience' (Charlesworth, 2000, p. 144). This involved a position of sharing thoughts and feelings and responding in sensitive and affirming 
ways to accounts of work experiences; the careful monitoring of our own language and non-verbal signs to convey sympathetic interest in a context where men are rarely given the opportunity to articulate their social experiences. Employing this model of reflexive engagement helped us to elucidate facets of occupational distance as well as gender difference (one researcher undertaking participant observation was female). In terms of the latter, rather than creating a gender based barrier between researcher and participant, feminist researchers (e.g. Evans, 2002) have suggested that women can offer a 'truer understanding' of men and masculinity on the grounds that their marginalised position means they are less imprisoned within established epistemological frameworks. As she argues, this marginalised position means women can offer a more comprehensive lens through an awareness of gendered power. In the context of this study, this lens facilitated, as example, recognition of how lack of power may be integrated with gendered culture and privilege as well as how men as gendered subjects create rituals, reaffirm symbolic differences and establish internal hierarchies. Further, the presence of the female researcher generated considerable interest (both from the participants and passers-by who mistook her for an 'ordinary' worker), helping to break down barriers and enabling an ease in terms of discussions, reflections and disclosures in the interview situation.

Thus, through 'active listening' and careful scrutiny of our own 'knowing practices' (Charlesworth, 2000, p. 31), we sought to afford voice to men's experiences in a context where, as Schwalbe and Wolkomir (2001) argue, male working class voices are rarely heard. In this way, drawing in particular on participant observation, on 'active listening' and 'reflexive engagement', we sought in Willis and Trondman's (2002) terms to trace 'responses to power' and of how they influence the research process. 


\section{Conclusion}

This paper set out to explore how ethnographic methods in the form of participant observation, interviews and photographic representation, can be usefully adopted in the context of researching dirty or undesirable work. Drawing on a study of refuse collectors, we highlight some of the meanings men attach to their work. In so doing our paper makes the following contributions.

Firstly, the paper offers fresh understandings of how dirt may be perceived by this group and gives empirical weight to previous research that has highlighted the significance of strong occupational ideologies in how such work is negotiated. In regards to the theoretical contribution of Douglas (1966), the empirical observations gained through this study reinforce the conceptualisation of dirt as a socially constructed phenomenon which is given meaning in context. It is not dirt in itself which 'offends against order' (Douglas, 1966, p. 45), but contingent and symbolic perception of dirt as a matter out of place that is a violation or corruption of cultural norms. The daily routine of handling refuse bags and the sensory experiences of the job (the smell, physicality and proximity to waste) is not seen as a matter out of place but part of the 'normalised domain'. It is only when the normalised experience was transgressed through the use of inappropriate bags or when dangerous objects (such as knifes, cut glass or excrement) were encountered that the label or 'dirt' was applied. Thus, the daily activities of refuse work have created a distinction between the 'orderly' and 'disorderly', imbuing perceptions of dirt only when these normative distinctions are transgressed. However, as Hughes (1958) has argued, men's spatial proximity to dirt can lead, in the eyes of the public, to rules of avoidance - evidenced through a lack of recognition afforded to the workers on the part of the local residents (whom they serve) as well as from the wider community. . Devaluation and lack of recognition affect the daily work experience and translate, arguably, into strong occupational cultures based on a shared camaraderie which helps to give meaning to work. 
Secondly, the paper draws on Willis and Trondman (2002) as a way of making sense of ethnographic method in a specific context. In order to study culture and experience, one must simultaneously represent society as the perpetual process of social integration and harmonious interaction (O'Reilly, 2005). The recognition of the role of theory was central to identifying the socially constructed meanings of dirt. Using the theoretical position of Douglas (1966), this project is able to generate a vision of dirt, not as an essential property in itself, but rather a product which is given meaning through context and socially negotiated experience. By reconstructing the nature of dirt within the boundaries of their work, the men are able to recreate the principle meaning within the activity of their labour. The centrality of culture locates the lived meanings of social groups in a temporal and spatial position in society. Broader cultural perceptions of dirt lead to a sustained lack of contact and recognition, impinging on notions of self-worth and a low social disposition which affects the work experience. Finally, the critical focus in research and writing allows for discourses of dirt to be situated in a wider social context, encapsulating the explicit lived in 'conditions of being' informed through social relations and constructions of power. As this study shows, refuse workers, despite performing an essential public service, the true condition of their experience is shaped by negatively imposed constructions of class and dirt which comes to define their labour. By incorporating these issues of theory, culture and reflexivity throughout the research process, this paper highlights how Willis and Trondman's (2002) approach aids the ethnographic objective and is crucial to the understanding of representation and experience.

Finally, and importantly, the paper shows how ethnography should be viewed as a collection of methods that aim to study the symbolic forms, patterns, discourses and practices of experience, located within a wider presentation of culture (O'Reilly, 2005; Brewer, 2000; Willis \& Trondman, 2002). To this end, the triangulation of participant observation, photographic representation and interviews enabled a fuller understanding of dirt and its routines than would have been otherwise 
possible. The use of field-notes recorded the daily ethnographic observations of the work, focusing on textures and feel for the routine as well as noting the general conversational flows that punctuated the day. The collection of interviews supported this position by offering us, the research team, the opportunity to focus on specific developments that interested us during the day as well as to gain further information of the work histories of the employees. Finally, photographs were used to offer a fixed caption of a moment in time, highlighting the particularities of work which aided the communication of the ethnographic experience. Incorporating these three processes aim to move beyond the ethnography as 'thick description' (Brewer, 2000) as well as the ethnographic fallacy of detailing the experiences of the researcher in a particular field of setting, opposed to the subjects in question (Bourdieu, 1984).

More broadly, this paper shows how ethnography represents an approach which aims to understand social experience through a sustained and interactive engagement with participants in the field. As such, the ethnographic process seeks to overcome linguistic barriers of expression in order to visualise social action as a sensory experience. By exploring the meanings which refuse collectors attach to their work, this paper has focused on a classed group that has arguably been invisible within both academic work and policy discourses. Seeking to capture the meanings that men attach to dirt and their experiences of dirty work, there are central points which can be translated beyond our frame of dirty work into other research contexts. The triangulation process, both in terms of method and Willis and Trondman's points of ethnographic inquiry, offer a basis for interpretation that can be applied to new research positions to aid the exploration of cultural experience in a given setting. 


\section{Bibliography}

Ashforth, B. \& Kreiner, G., 1999. "How can you do it?" Dirty Work and the Challenge of Constructing a Positive Identity. Academy of Management Review, 24(3), pp. 413-434.

Atkinson, P., Coffey, A., Delamont, S., Lofland, J. \& Lofland, L., 2001. Handbook of Ethnography. London: SAGE.

Bolton, S. \& Houlihan, M., 2009. Work Matters: Critical Reflections on Contemporary Work. Basingstoke: Palgrave Macmillan.

Bourdieu, P., 1984. Distinction: A Social Critique of the Judgement of Taste. London: Routledge.

Brewer, J., 2000. Ethnography. Buckingham: Open University Press.

Charlesworth, S., 2000. A Phenomenology of Class. Oxford: Oxford University Press.

Connell, R., 2000. The Men and the Boys. Cambridge: Polity Press.

Connell, R., 2005. Masculinities. $2^{\text {nd }}$ ed. Berkeley, CA: University of California Press.

Cunliffe, A., 2003. Reflexive Inquiry in Organisational Research: Questions and Possibilities. Human Relations, 56(8), pp. 983-1003.

Dalton, D., Daily, C. \& Wimbush, J., 1997. Collecting Sensitive Data in Business Ethics Research: A Case for the Unmatched Count Technique. Journal of Business Ethics, 16(10), pp. 1049-1057.

Dick, P., 2005. Dirty Work Designations: How Police Officers Account for their use of Coercive Force. Human Relations, 58(11), pp. 1363-1390.

Douglas, M., 1966. Purity and Danger: An Analysis of Concepts of Pollution and Taboo. London: Routledge.

Evans, J., 2002. Cautious Caregivers: Gender Stereotypes and the Sexualization of Men Nurses' Touch. Journal of Advanced Nursing, 40(4), pp. 441-448.

Fabian, J., 1983. Time and the Other: How Anthropology Makes its Object. New York: Columbia University Press.

Flick, U., 2007. Designing Qualitative Research. London: SAGE. 
Gregg, P. \& Wadsworth, J., 2003. Labour Market Prospects of Less Skilled Workers Over the Recovery. In: R. Dickens, P. Gregg \& J. Wadsworth, eds. The Labour Market Under New Labour: The State of Working Britain. Basingstoke : Palgrave Macmillan, pp. 86-98.

Hammersley, M. \& Atkinson, P., 1983. Ethnography: Principles in Practice. London: Tavistock Publications.

Harper, D., 2002. Talking About Pictures: A Case for Photo Elicitation. Visual Studies, 17(1), pp. 13-26.

Hughes, E., 1958. Men and their Work. Glencoe, IL: Free Press.

Karnielie-Miller, O., Strier, R. \& Pessach, L., 2009. Power Relations in Qualitative Research. Qualitative Health Research, 19(2), pp. 279-289.

Kvale, S. \& Brinkmann, S., 2009. InterViews: Learning the Craft of Qualitative Research Interviewing. 2nd ed. London: SAGE.

Lee, R., 1993. Doing Research on Sensitive Topics. London: SAGE.

McDowell, L., 1997. Capital Culture: Gender at Work in the City. Oxford: Blackwell Publishers.

McDowell, L., 2003. Redundant Masculinities: Employment Change and White Working Class Youth. Oxford: Blackwell.

Neyland, D., 2008. Organizational Ethnography. London: SAGE.

ONS, 2010. Standard Occupational Classification 2010. Volume: 1 Structure and Descriptions of Unit Groups. London: s.n.

O'Reilly, K., 2005. Ethnographic Methods. London: Routledge.

Reay, D., 1998. Rethinking Social Class: Qualitative Perspectives on Class and Gender. Sociology, 32(2), pp. 259-275.

Roberts, K., 2001. Class in Modern Britain. Basingstoke: Palgrave.

Saunders, M. \& Thornhill, A., 2011. Researching Sensitive Issues Without Sensitising: Using a Concurrent Mixed Methods Design to Research Trust and Distrust. International Journal of Multiple Research Approaches, 5(3), pp. 334-350.

Savage, J., 2000. Ethnography and Health Care. British Medical Journal, Volume 321, pp. 1400-1402. 
Schwalbe, M. \& Wolkomir, M., 2001. The Masculine Self as Problem and Resource in Interview Studies of Men. Men and Masculinities, 4(1), pp. 90-103.

Sennett, R. \& Cobb, J., 1972. The Hidden Injuries of Class. Cambridge: Cambridge University Press.

Skeggs, B., 1997. Formations of Class and Gender. London: Sage.

Skeggs, B., 2004. Class, Self and Culture. London: Routledge.

Slutskaya, N., Hughes, J. \& Simpson, A., 2012. Lessons from Photoelicitation: Encouraging Working Men to Speak. Qualitative Research in Organizations and Management: An International Journal, 7(1), pp. 16-33.

Strauss, A. \& Corbin, J., 1990. Basics of Qualitative Research: Grounded Theory Procedures and Techniques. London: SAGE.

Taylor, S. \& Bodgan, R., 1984. Introduction to Qualitative Research Methods: The Search for Meanings. New York: Wiley.

Thompson, E., 1978. Poverty of Theory. London: Merlin.

Tyler, M., 2012. Clamour Girls, Macho Men and Everything in between: Un/going Gender and Dirty Work in Soho's Sex Shops. In: R. Simpson, N. Slutskaya, P. Lewis \& H. Hopfl, eds. Doing Dirty Work: Concepts and Identities. Basingstoke: Plagrave.

Wacquant, L., 2004. Body and Soul: Notebooks of an Apprentice Boxer. Oxford: Oxford University Press.

Willis, P., 1977. Learning Labor: How Working Class Kids get Working Class Jobs. New York: Columbia University Press.

Willis, P. \& Trondman, M., 2002. Maifesto for Ethnography. Cultural Studies - Critical Methodologies, 2(3), pp. 394-402.

Wolcott, H., 1973. The Man in the Principal's Office: An Ethnography. Oxford: AltaMira Press.

Wrzesniewski, A., 2003. Finding Positive Meaning in Work. In: K. S. Cameron, J. E. Dutton \& R. E. Quinn, eds. Positive Organisational Scholarship. San Francisco: Berrett-Koehler.

Ybema, S., Yanow, D., Wels, H. \& Kamsteeg, F., 2009. Organizational Ethnography: Studying the Complexity of Everyday Life. London: SAGE. 
Zukin, S. \& DiMaggio, P., 1990. Structures of Capital: The Social Organisation of the Economy. Cambridge: Cambridge University Press. 